\title{
IV Taller de Editores de Revistas - Red Iberoamericana de Editores de Revistas
}

\author{
Carolina Negrete Rodríguez ${ }^{1}$
}

El martes 26 de octubre tuvo lugar en la ciudad de Mendoza, Argentina, el IV Taller de Editores de Revistas de la Red Iberoamericana de Editores de Revistas (RIER), en el marco del XI Seminario Internacional de la Red Iberoamericana de Investigadores sobre Globalización y Territorio (RII), organizado por la Facultad de Filosofía y Letras y el Instituto de Ciencias Ambientales de la Universidad Nacional de Cuyo y el Instituto de Cartografía, Investigación y Formación para el Ordenamiento Territorial.

En esta ocasión el taller se dividió esencialmente en dos bloques. El primero de ellos se compuso de dos secciones, estando la primera orientada a la recapitulación de los objetivos del IV taller RIER derivados del último encuentro realizado en Querétaro en 2008 y a la contextualización del estado actual de las revistas científicas en ciencias sociales; asimismo el seminario contó con la mirada del CONICET de Argentina acerca de los requerimientos básicos en términos de calidad editorial y de contenidos en publicaciones periódicas científicas. La segunda sección, Ilamada Estrategias para el mejoramiento de procesos editoriales, se adentró en aplicaciones a problemas concretos que se enfrentan en el proceso cotidiano de gestión editorial. Se puso énfasis principalmente en la estandarización de normas de revistas científicas y en el cumplimiento de los requisitos básicos y mínimos para obtener una cierta calidad editorial y con ello sentar las bases para avanzar en el camino hacia las indizaciones. En este contexto se discutieron y abordaron procesos tales como elementos básicos en las páginas de presentación de cualquier revista científica, definición de ámbitos temáticos y público objetivo, explicitación (en normas de publicación) del proceso de dictamen de la revista, declaratorias de originalidad y no envío simultáneo de artículos a más de una revista y cesión de derechos de autor, junto a diversas estrategias de operación para ampliar las carteras de árbitros e intercambiar publicidad, entre otros.

El segundo bloque consistió también en un taller aplicado, Ilamado Estrategias para atención de problemas concretos en el uso de Open Journal System, que estuvo dedicado exclusivamente a la incorporación de tecnologías al proceso de gestión editorial, por medio de la utilización del software OJS (Open Journal System) creado especialmente para agilizar la gestión editorial. En este contexto se trató la resolución de problemas relacionados con: la instalación del software; la personalización de etapas del proceso editorial y asignación de funciones editoriales; el acceso a manuscritos en preimpresión, el registro de las revistas en el indizador de OJS; la habilitación de revisores; el contacto para asistencia técnica, reportes de error y sugerencias de mejora; e identificación de manuales para el uso de OJS.

La actividad contó con la presencia de editores y colaboradores de revistas relacionadas con temas territoriales pero también de otras áreas de las ciencias, de distintos países de Latinoamérica.

\footnotetext{
1 Instituto de Geografía, Pontificia Universidad Católica de Chile (Chile). E-mail: cnegrete@geo.puc.cl
} 